
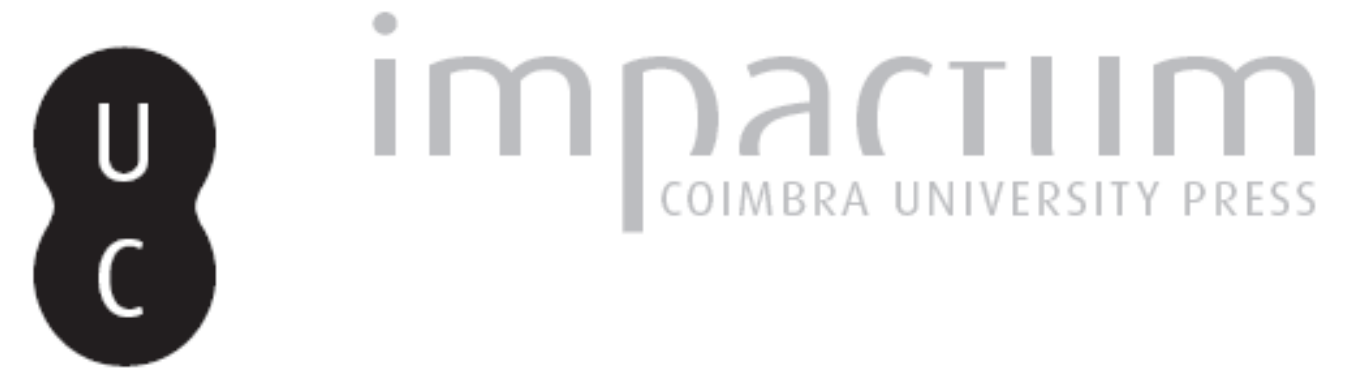

\title{
Onde há fogo, nós levamos gasolina
}

\section{Autor(es): $\quad$ Bandeira, Pedro}

Publicado por: Editorial do Departamento de Arquitetura

URL persistente:

URI:http://hdl.handle.net/10316.2/37487

DOI:

DOI:http://dx.doi.org/10.14195/0874-6168_5_7

Accessed : $\quad$ 26-Apr-2023 11:13:48

A navegação consulta e descarregamento dos títulos inseridos nas Bibliotecas Digitais UC Digitalis, UC Pombalina e UC Impactum, pressupõem a aceitação plena e sem reservas dos Termos e Condições de Uso destas Bibliotecas Digitais, disponíveis em https://digitalis.uc.pt/pt-pt/termos.

Conforme exposto nos referidos Termos e Condições de Uso, o descarregamento de títulos de acesso restrito requer uma licença válida de autorização devendo o utilizador aceder ao(s) documento(s) a partir de um endereço de IP da instituição detentora da supramencionada licença.

Ao utilizador é apenas permitido o descarregamento para uso pessoal, pelo que o emprego do(s) título(s) descarregado(s) para outro fim, designadamente comercial, carece de autorização do respetivo autor ou editor da obra.

Na medida em que todas as obras da UC Digitalis se encontram protegidas pelo Código do Direito de Autor e Direitos Conexos e demais legislação aplicável, toda a cópia, parcial ou total, deste documento, nos casos em que é legalmente admitida, deverá conter ou fazer-se acompanhar por este aviso.

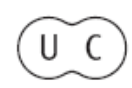




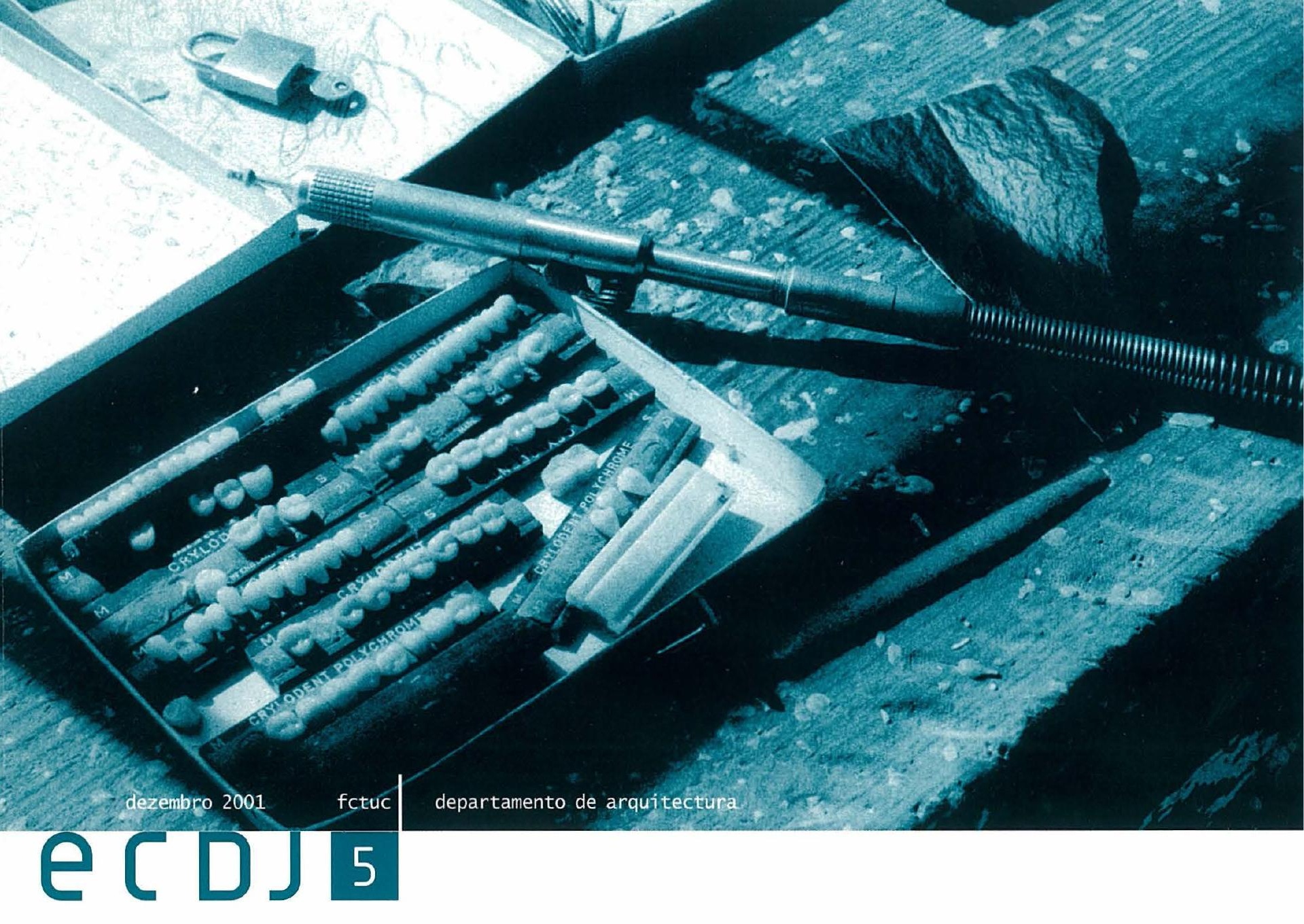

\section{investigação em arquitectura [?]}

George Teyssot

Paulo Providência | Mário Krüger | Wałter Rossa | António olaio

Outra abertura adelino gonçałves

Sti11Life, duração e abandono na obra de john hejduk francisco ferreira

Onde há fogo, nós levamos gasolina pedro bandeira

Apontamentos sobre a arquitectura religiosa do séc. XX em Portugal cidália silva

o desafio ecológico luís pinto faria

Pescada de rabo na boca patrícia miguel carvalho

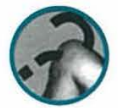



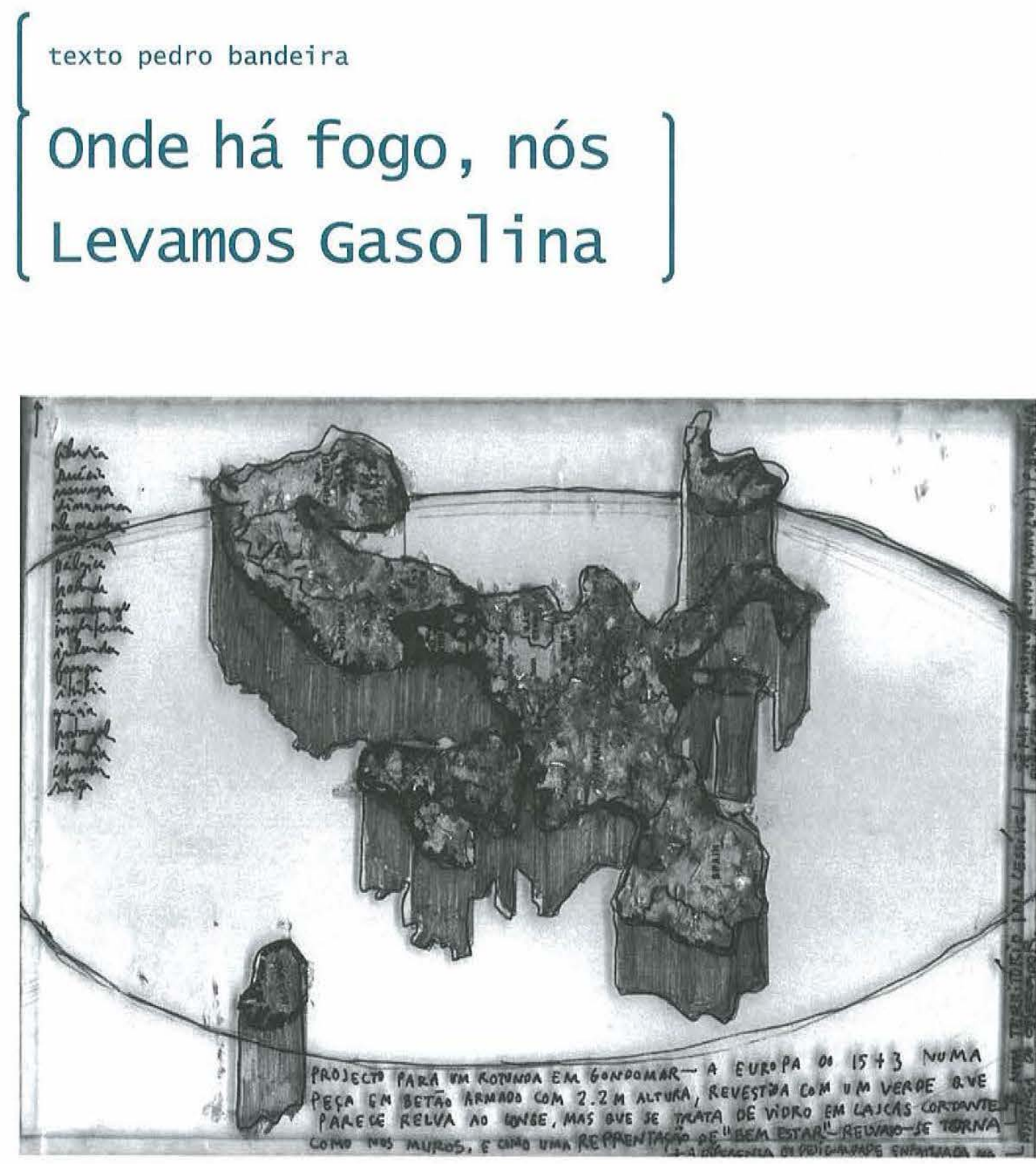


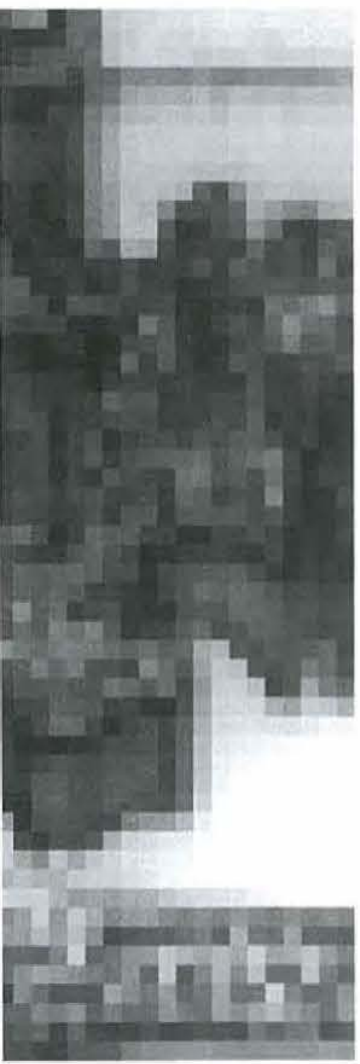

A mental disease has swept the planet: banalization (...) Darkness and obscurity are banished by artificial lighting, and the seasons by air conditioning; night and summer are loosing their charm and dawn is disappearing. The man of the cities thinks he has escaped from cosmic reality, but there is no corresponding expansion of his dream 1ife. The reason is clear: dreams spring from reality and are realized in it (...)

The architecture of tomorrow wil1 be a means of modifying present conceptions of time and space. It wi11 be a means of knowledge and means of action. The architectural complex will be modifiable. Its aspect witl change totally or partially in accordance with the wi11 of its inhabitants (...) We have already pointed out the need of constructing situations as being one of the fundamental desires on which the next civilization will be founded. This need for absolute creation has always been intimately associated with the need to play with architecture, time, and space. (1) 
1. Em 1953, Ivan Chtcheglov, no texto pré-situacionista Formulary for a New urbanism (publicado 5 anos depois na I.S. \# 1, sob o pseudónimo de Gilles Ivain), reclamava uma arquitectura capaz de proporcionar alternativas à banalidade do quotidiano, reivindicando para o utente a criação do próprio espaço e apelando a uma certa perda de orientação, no sentido da recusa de uma lógica imediata das coisas, valorizando, por exemplo, a consciência de algo através da sua ausência. Este texto, próximo do pensamento de Henri Lefebvre, que em 1947 pub7icava critique de Ta vie Quotidienne, seria referência incontornáve1 da Internacional situacionista, quer no projecto para a Nova Babilónia (uma crítica ao estilo internacional legitimada nos desejos individuais e numa cultura do ócio ), quer na teoria da Dérive (1956) de Guy Debord, pub7icada dois anos depois na I.S. \#2.

Embora posteriormente preso por planear explodir a Torre Eiffel e mais tarde internado num hospital para doentes mentais, Ivan chtcheglov, lançava o mote para uma geração de arquitectos do Tate modernism: modernismo tardio, modernismo latente.

Preso por planear explodir a Torre Eiffel e mais tarde internado num hospital para doentes mentais.

> A Internacional situacionista foi fundada em cosio d'Arroscia, Itália, no ano de 1957 por Guy Debord, Asger Jorn, Giuseppe Pinot-Gallizio, Michèle Bernstein, wa7ter 01mo, Elena Verrone, e Piero Simondo representando a fusão de três grupos distintos mas com semeThantes ambições: a Internaciona1 Letrista; o Movimento Internacional por uma Bauhaus Imaginista; e o comité Psicogeográfico de Londres.

> A Internaciona1 Letrista apresentava-se como extensão, mas também alternativa, dos "velhos" Letristas de Isidore Isou (nascido na Roménia em 1924) que pretendiam levar às últimas consequências a autodestruiçăo das formas artísticas iniciadas por Baudelaire, ou seja, a redução da poesia ao seu elemento último - a letra (2). o grupo de Isou era especialmente conhecido pelas suas intervenções polémicas em forma de sabotagem de acontecimentos púb7icos; inaugurações de exposiçöes; peças de teatro; festivais de cinema; enfim, um rol de escândalos dos quais a declaração da «morte de Deus» (3), efectuada por um falso frade dominicano na Páscoa de 1950, em plena igreja da Notre-Dame de Paris, acabaria por chamar a atenção de Guy Debord, que proporia de imediato a sua colaboração com o grupo de Isou.

> Em 1952 Debord estreia o filme Hurlements en Faveur de Sade, uma colagem de citaçōes sobre um ecrã ora branco ora negro, interrompido por momentos de silêncio e obscuridade total (24 longos minutos) que deixaram o púb7ico num estado de revolta e indignação total, mas não sem pré-aviso; no início do filme podia ler-se «O cinema morreu. Não podem haver mais filmes. 
Passemos então ao debate» (4). No mesmo ano em que John Cage compunha os 4'33' ' de silêncio, Debord desenvolvia o seu interesse por criar situações (daí o posterior sentido situacionista) em que a revolta deixava para trás o conformismo do tradicional espectador, instigando a sua participaçăo e a criaçăo de momentos (Henri Lefebvre). o cinema (assim como toda a arte) seria a partir daqui um mero pretexto para atingir uma revoluçăo cultural e social. o debate proposto pela Internacional Letrista de Debord evidenciava uma maior preocupaçăo social na reivindicação da vida vivida; um quotidiano de prazer, criação e aventura; a vida como arte e năo arte como vida. A arte em si estaria esgotada, nada tinha ficado, supostamente, por dizer após Malevitch, ou outras vanguardas do início do século, nada poderia ser verdadei ramente novo (5). obviamente, deveremos ainda enquadrar este manifesto numa expressiva recusa do que se tornaria o estilo de vida dos anos 50 ; métroboulot-dodo (transporte, trabalho, casa) coexistindo, indiferentemente, com uma elite de artistas acomodados a uma sucessão de espectáculos sem consequências. Este desequilíbrio entre supostos actores e passivos espectadores, aproximaria a Internacional Letrista da construção da beleza das cidade e dos seus rostos.

> É neste contexto que surge a teoria da Dérive; uma prática de deambular por ambientes variados, que já estava expressa no Formulary for a New Urbanism "the changing of Tandscapes from one hour to the next". Embora sujeita à atracção espontânea que determinados elementos de um território possam sugerir, a dérive deveria ser acompanhada de uma reflexão psicogeográfica (6), baseada no redesenho de mapas, instigando, deste modo, uma maior consciência sobre as possibilidades e variantes do território, suprimindo Timites e zonas de fronteira convencionais.

> "The lessons draw from the dérive permit the drawing up of the first surveys of the psychogeographical articulations of a modern city. Beyond the discovery of unites of ambiance, of their main components and their spatial localization, one comes to perceive their principal axes of passage, their exits and their defenses. One arrives at the centrat hypothesis of the existence of psychogeographical pivotal points. One measures the distances that effectively separate two regions of a city, distances that may have little relation with the physical distance between them. (..) Today the different unites of atmosphere and of dwellings are not precisely marked off, but are surrounded by more or less extended and indistinct bordering regions. The most general change that dérive leads to proposing is the constant diminution of these border regions, up to the point of their complete suppression." (7) 
> Esta proposta de Debord implicava um estudo que, pouco a pouco se desvincularia da mera casualidade na escolha de percursos; a dérive deveria contribuir para uma clarificação de opções capazes de expressar, não uma subordinaçăo à casualidade, mas uma total insubordinaçăo às referências habituais, na recusa de percursos diários, turísticos, Tugares comuns ou, de um modo genérico, a recusa de um uso monótono ou rotineiro da cidade.

> Deste modo deixaria de ser apenas um jogo de desorientaçăo expresso na excentricidade do "deixar-se vaguear por uma região orientando-se por um mapa de uma localização distante" para ser antes uma ciência psicogeografia com cartografia própria, capaz de expressar com rigor a relação emocional com o espaço urbano, como poderão demonstrar os mapas concebido entre 1957 e 1959 por Debord e Asger Jorn.

> É evidente, na teoria da dérive, uma vontade de trabalhar sobre o território rea1, existente, reivindicando o espaço público como o lugar de criação cultural e acção política (8). Esta "devolução" do espaço público aos cidadãos está igualmente implícita na proposta de Marien (Les Lèvres Nues \# 6 1955) em armazenar num deserto todas as estátuas equestres que ornamentam as praças do mundo, deixando a sensaçăo que o hipotético espaço livre dos monumentos, poderia vir a pertencer a qualquer transeunte. Segundo Debord, a cavalaria artificial, isolada, poderia ainda fazer uma bizarra "homenagem" aos grandes massacres históricos.

> A dérive era a evidência da aceitação do espaço existente como lugar pleno de possibilidades. A sua prática recomendava o uso de todos os meios e tecnologias disponíveis, embora subvertendo algumas lógicas. Por exemplo, entrar num táxi não implicaria mencionar um lugar mas antes um tempo: "Teve-me 20 minutos para oeste", de modo a favorecer um destino vago e inesperado.

> 2. A Internacional situacionista privilegiou o espaço público como o seu campo de bataTha, reivindicando transformaçōes, praticando acçöes, avançando com propostas e estabelecendo uma regular e atenta crítica urbana com o sentido de alcançar uma subversão maciça. É sobre este propósito que é sedimentado o urbanismo unitário (U.U.), não como uma doutrina urbanística mas antes uma crítica do urbanismo (nenhuma disciplina separada pode ser aceite em si mesma, avançamos para a criaçăo global da existência), Uma reorientação programática das teorias funcionalistas levará à eleição da função «jogo», associado ao ócio, enquanto actividade privilegiada do urbanismo unitário: um jogo de emoções, de comunicação e criatividade.

> "o urbanismo unitário opöe-se ao espectáculo passivo, princípio da nossa cultura, na qual a organização do espectáculo se vai alargando mais escandalosamente conforme vão aumentando os meios de intervenção humana. Ao passo que nos nossos dias as próprias cidades existem como um lamentável 
espectáculo, um suplemento museológico para turistas passeados em autocarros de vidro, o urbanismo uni tário encara o meio ambiente urbano como terreno dum jogo em participação. o urbanismo unitário não está ideałmente separado do terreno actual das cidades. Forma-se a partir da experiência deste terreno e a partir, também, das construções existentes. Devemos explorar os cenários actuais, peła afirmação de um espaço urbano lúdico cujo reconhecimento a deriva estabelece, tanto como deveremos construir cenários intei ramente inéditos. Esta interpenetraçăo (utilizaçăo da cidade presente, construção da cidade futura) implica o manejo do desvio arquitectura1. o U.u. opöe-se à fixação das cidades no tempo, levando, pelo contrário, a que se preconize a sua transformação permanentemente (...) ० U.U, oposto à fixação das pessoas em pontos determinados duma cidade, constitui o pedesta1 duma civilização do ócio e do jogo." (9)

> A história do movimento moderno tornou-se, para os situacionistas, numa desilusão de expectativas; ao contrário da 7iberdade supostamente subjacente à automatização (10) - a eterna crença na máquina os avanços tecnológicos resultavam numa inibiçăo da criatividade individual e mesmo as propostas de "homogeneização" dos espaços públicos, ao contrário de fomentar uma igualdade social, demonstravam-se segregativos, inibindo as acçőes de carácter colectivo e participativo. Usando o humor como propaganda os situacionistas contrapropunham: se a iluminaçăo é púb7ica, então, porque é que não tem interruptores para uso público?

Se a iluminação é púb7ica, então, porque é que não têm interruptores para uso púb7ico?

> Outros argumentos distanciavam os situacionista do movimento moderno: embora oposto à sacralizaçăo da cidade, o U.u. era contrário a uma ruptura radical com o passado, como era expresso, por exemplo, nos planos de Le corbusier. As reivindicaçōes para os espaço urbano năo passavam por uma destruição género tabula rasa, mas antes numa transformação ou apropriaçăo do território herdado. Esta aceitação ou vontade implicaria um método de reciclagem ou détournement (11) conforme testemunha o plano para um Racional Aperfeiçoamento da Cidade de Paris (12), pub1icado na Pot7ach $n^{\circ} 23$ :

> o metropolitano e jardins públicos deveriam permanecer abertos toda a noite, assumindo-se como espaços de residência ou locais de dérive;

> as coberturas de paris deveriam ser acessíveis ao tráfego pedestre, usando escadas de incêndio ou passagens aéreas;

> os museus deveriam ser abolidos sendo as suas obras distribuídas por cafés;

> os cemitérios deveriam ser eliminados (no ashes and no remains); 
as igrejas deveriam ser demolidas ou transformados os seus usos, enfatizando a Tibertação religiosa do homem;

estaçōes de comboios poderiam permanecer como estão à excepção de um pormenor; as tabelas dos horários deveriam desaparecer ou ser desorganizadas com o sentido de promover a dérive. Afinal, as revoluções francesas não começavam com a destruição dos relógios públicos? Precisamente contra a tirania do tempo?

> Legitimado como terapia pós-guerra, o humor era usado como arma, reivindicando, simultaneamente, uma cultura de ócio (ne travaillez jamais! (13)) para um novo Homo Ludens termo inicialmente usado por Johan Huizinga, no Tivro A Study of Play Element in culture, referindo-se a elementos das classes altas (the propertied leisure class) e posteriormente adaptado pelo artista holandês constant Nieuwenhuys que proporá uma abordagem mais abrangente para uma civilização Túdica: um humanismo 1ibertário e criativo, que deveria saber contornar os aspectos acessórios da vida corrente: "parecenos evidente que não se deve encorajar a permanente renovaçăo artística dos frigoríficos" até porque "a beleza quando năo sustenta a promessa de felicidade deve ser destruída".

"A beleza quando não sustenta a promessa de felicidade deve ser destruída".

3. No início da década de 50 Constant Nieuwenhuys iniciava o projecto do que viria a ser conhecido por Nova Babilónia (nome proposto com alguma provocação, por Debord, pois, para os protestantes, a tradicional Babilónia representa a cidade perversa) partindo do princípio que a arquitectura instrumento de emoçōes deveria instigar a transformaçăo do quotidiano através da criação de acontecimentos ou situaçōes. A Nova Babilónia assumiu, por momentos, a imagem da sedimentação dos princípios do urbanismo unitário (Declaração de Amsterdão, Dezembro de 1958), antecipando uma forma espacia1 vinculada à iminente revoluçăo social. Em 1959, constant, publicava dois textos (The Great Game to Come, in Potlatch $n^{\circ} 30$ e Another city, Another Life, in I.S. $n^{\circ}$ 2) em que a partir de uma crítica à ville verte (14), propunha como alternativa, usando as suas palavras, uma arquitectura de ficção científica.

> Para Constant a citté radieuse preocupava-se, essencialmente, com duas funçōes circulaçăo e habitação tratadas de um modo separado que, consequentemente, produziam uma reduzida variaçăo de ambientes. o facto de, neste conceito de cidade, proliferarem os edifícios altos e distanciados, contribuía para o declínio das acções e relações directas entre indivíduos. 
> A grande escala e a homogeneização do espaço público, associada à erradicação da rua tradicional, beneficiava um uso exclusivo do automóve1, privilegiando ambientes socialmente isolados.

> A Nova Babilónia, acumulando as experiências psicogeográficas da dérive, proporia uma urbanidade sensível à criatividade individual e partithada como experiência colectiva. Partindo de uma forma espacial dinâmica (máximo de elementos amovíveis), a proposta, enfatizava a capacidade de proporcionar uma diversidade de ambientes e transformaçöes que acompanhassem as complexas exigências de uma estrutura social fundamentada num espaço capaz de absorver os desejos ou emoções dos seus utentes. Neste espaço qualquer cidadão teria um papel activo na permanente criação de ambientes e na possibilidade de renovação espacial. Politicamente, seria a elevação de um urbanismo-participativo, não fosse a efemeridade das situações trair o sentido temporal de planeamento, privilegiando, antes, o acaso.

> Constant, ainda próximo de uma herança moderna progressista, propunha uma dupla aquisição dos avanços tecnológicos: năo só a automatização deveria 1ibertar o homem do trabalho, como servir de instrumento para a construção de novas realidades através do potencial oferecido pelo cinema, televisăo, rádio, novas fontes de energias, iluminaçăo, som ou ar-condicionado. Esta crença implicaria que a Nova Babilónia fosse capaz de suplantar a própria natureza, não estando subjugada a condicionantes climáticas, ou outras, podendo igualmente abdicar do dia ou da noite. Esta megaestrutura elevada do solo, não conheceria quaisquer fronteiras ou limites, desenvolver-se-ia continuamente por todo o planeta e os seus habitantes seriam nómadas.

> Até 59 constant desenvolve sectores abstractos, sem localizaçăo específica (New Babylon Nord, orient Sector, Rode sector, yellow zone, etc.) que săo uma plataforma prévia de um faseamento até atingir a desejada revolução social global.

> Em 4 de Maio 1959, Constant exibia no Stedelijk Museu de Amesterdão, 30 modelos organizados cronologicamente, em que era notória a evolução entre uma primeira fase da mostra de Self-sufficient Merchandise-objects "só para olhar" e uma segunda fase de Project-objects objectos cujo valor passava, obrigatoriamente, pelo entendimento dos objectivos do urbanismo unitário, e que isoladamente não deveriam conter qualquer valor artístico.

> Constant, por diversas vezes, e desde logo no grupo CoBrA, tinha manifestado convicção de que o uso das técnicas artísticas tradicionais, só teriam sentido como um instrumento para atingir determinados objectivos, recusando a ideia de que a pintura, escultura ou música pudessem ser um fim em si mesmo. Alertava, ainda, para a consciência de que estes objectos apenas se Timitavam a representar um momento específico e redutor do seu projecto dinâmico: às três dimensões dos modelos faltava uma quarta; o tempo. 
> 0 passado artístico de muitos elementos da I.S e o facto de várias exposições situacionistas se realizarem em espaços institucionalizados pela arte convencional pouco contribuiria para uma clarificação dos objectivos políticos do movimento, começando a criar alguma ambiguidade ou mesmo incompatibilidade. Embora numa primeira fase Debord tivesse incentivado essas mostras, mais tarde a sua ortodoxia (quem sabe algo receosa da notoriedade que a fracçăo artística conquistava) evoluía para um distanciamento de constant, entre outros.

> Posteriormente, Constant atreveu-se a publicar num catálogo editado pelo Museu Municipal de Bochum, um projecto para uma fábrica (instituição supostamente representante da escravidão do traba7ho) e dois dos seus colaboradores aceitaram projectar uma igreja, provocando uma incompatibilidade que levaria, no verão de 1960, à sua demissẵo sob fortes críticas:

> "This cunning sout (Constant), among two or three plagiarism's of badly understood situationist ideas, shamelessly offers himself as a publicrelations man for integrating the masses into capitalist technical civilization, and reproaches the S.I. for having abandoned his whole program for shaking up the urban environment, which he would remain the sole person to be occupied with". (15)

> Note-se que dos cerca de 70 membros que fizeram parte da Internacional Situacionista, 19 demitiram-se e 45 foram expulsos por Guy Debord (16).

> Esta ruptura com a I.S não inibirá a evolução da Nova Babilónia, constant adoptará uma persona hyper-architectural (17), integrando o GEAM de Yona Friedman, desdobrando-se em conferência sempre com a leitura inicial do seu manifesto e posterior projecçäo de slides tirados de maquetas. Em 1963 esta arquitectura do desejo começa a conquistar localizações específicas Amesterdão, Barcelona, Antuérpia, Paris - numa prática em que poderíamos reconhecer algum sentido de détournement. A coexistência com a cidade tradicional seria temporária, pois o sentido era alcançar a fase de absoluta autonomia e substituiçăo; uma teia à escala planetária para indivíduos nómadas (lembramos que as comunidades ciganas eram referência de constant). A abolição de fronteiras e, consequentemente, de nações enfatizaria uma promiscuidade de populações até ao ponto, no Timite, de não existirem diferentes raças, nem diferentes identidades sociais, o Homo Ludens seria único e universa1. A propriedade seria unicamente colectiva, assim como os meios de produçăo totalmente automatizados. o colectivo (em abstracto) teria ainda controle sobre a racionalização de bens de consumo. 0 espaço social seria verdadeiramente o espaço de encontros, de contactos entre seres; spatiality is social. A educação na Babilónia seria feita através da aprendizagem, do jogo e da espontaneidade criativa que, segundo constant, consiste na sublimação dos primeiros instintos, justificando porque as 
crianças são mais criativas que os adultos. Na Nova Babilónia perder-se-ia a noçăo de tempo, em benefício de uma dilataçăo do espaço, infinito como uma geometria fractal. Apesar dos contornos utópicos, assentes numa ilusória interpretação da realidade social, lembramos um apelo de constant publicado na I.S $n^{\circ} 2$ :

> "If the project we have just traced out in bold strokes risks being taken for a fantastic dream, we insist on the fact that it is feasible from the technical point of view, that it is desirable from the human point of view, that it wil1 become indispensable from the social point of view. The increasing dissatisfaction which dominates the whole of humanity wi11 arrive at a point where we will a11 be forced to execute projects whose means we possess; and which wi11 contribute to the realization of a richer and more fulfilled life."

"The project we have just traced out in bold strokes risks being taken for a fantastic dream."

4. Do outro lado da mesma moeda, Guy Debord escrevia La Societe du Spectacle (que ainda hoje continua a servir de referência a um discurso contrário ao pensamento único, ao neoliberalismo, ou a uma forma de globalização alienante) que é também uma renuncia à ideologia revolucionária inverosími1, temendo a ineficácia de, como qualquer outra ideologia, assentar numa vontade demasiado abstracta do universal, ou seja, distanciada das realidades especificas. Para Debord, reinventar a revolução passaria por uma actuação a diversos níveis, abrangendo valores genéricos e respostas pontuais, estimulando um empenhamento generalizado e uma actuação assente em micro-geografias. Só a crítica em permanente actualização, legitimaria um processo dinâmico para uma revolução do quotidiano.

* A consciência do domínio autocrático da economia mercanti1, capaz de ultrapassar qualquer fronteira ou sistema de governo, Tevaria Guy Debord a propor uma guerra total em que todas as classes teriam uma pape1 a desempenhar pela construção de uma sociedade sem classes assumindo como incontornáve1 um período de transição, mas em que os artistas năo teriam um papel distinto no processo revolucionário. Nem artistas nem terroristas: Debord, que se correspondia com as Brigadas Vermelhas Italianas, questionará a eficiência de uma revolução conquistada à bomba, temendo que o terror beneficie, perversamente, o poder criticado. Esta lucidez impedirá que se refugie em reivindicaçōes utópicas, acreditando (pe1o menos até 68) que a realidade existente será suficiente para incitar à revolução, como dirá Beuys a revoluçã̃o somos nós. 
> Mas, se Debord se retira num posterior cepticismo, a Nova Babilónia ausentase, partithando com a realidade apenas uma proximidade geográfica. A defesa de um processo de imaginação conquistado diariamente, defendido por Debord, opor-se-á um imaginário Tongínquo de constant, que elege a imagem como ałternativa ao rea1, correndo deste modo o risco de distrair uma efectiva acção directa (a forma perverte a função). Perversamente, este universo das imagens é o que melhor serve a sociedade da acumulação dos espectáculos, ou seja da representatividade por excelência (a confrontação de abstracções ideológicas é a linguagem instituída do poder).

> Pelo contrário "todo o imenso trabalho teórico de crítica social de Debord năo pretende ser discurso algum da utopia instrumentalizada, näo formula nenhum anúncio de um mundo por vir enfim salvo e iluminado, na medida em que se constitui como um diagnóstico sem reservas e sem calculismos da realidade. Porque não pode ser nunca reconduzido à forma de manual de um novo-outro poder. Como que a dizer-nos que a discussão da alternativa esconde a crítica da realidade presente." (18)

> No capítulo A ordenação do Território de A Sociedade do Espectáculo, Debord começa por abordar, precisamente, um défice de tempo associado a uma noção de espaço; a mesma modernização que retirou da viagem o tempo, retirou-1he também a realidade do espaço. Se o mundo encolhe a uma escala global nas suas relaçōes económico-sociais (como aparentemente poderia apontar a tese da aldeia global de McLuhan, ou mais recentemente o cibermundo de virilio), por outro 1ado, à escala do 1ocal, generaliza-se a política da separaçăo; distâncias interiores, conscientemente dispersivas ou dissuasivas. o poder, apostando na separação de classes, intensifica uma correspondente separação territorial. Surge a localização periférica da classe trabalhadora, deliberadamente distanciada do espaço público da cidade, o espaço da possível revolta. Esta sociedade que suprime a distância geográfica, recothe interiormente a distância, enquanto separação espectacular. Ainda segundo Debord, este controle social, estará associado ao urbanismo enquanto técnica ou especialidade da separaçăo e controle simultâneo do indivíduo (segundo os interesses capitalistas da estabilidade, produção e consumo).

Esta sociedade que suprime a distância geográfica, recolhe interiormente a distância, enquanto separação espetacular. 
> "o urbanismo é a concretização moderna da tarefa ininterrupta que salvaguarda o poder de classe: a manutençăo da atomização dos trabalhadores que as condiçōes urbanas tinham perigosamente reunido. A Tuta constante que teve de ser levada a cabo contra todos os aspectos desta possibilidade de encontro descobre no urbanismo o seu campo privilegiado. o esforço de todos os poderes estabelecidos desde as experiências da Revolução francesa, para aumentar os meios de manter a ordem na rua, culmina finalmente na supressão da rua." (19) > Debord confrontará ao espectáculo a radicalidade da verdade, nunca a utopia. Acreditando que tudo o que é preciso para a revolução já existe na realidade, apenas bastará desvendar através de uma crítica imanente, uma invenção que significa confrontar a realidade da sociedade com as suas promessas e pretensões.

5. Pouca ou nenhuma arquitectura adveio da Internacional situacionista interessava, primeiro, saber quem pegou fogo à capela da Sorbone durante os 2 dias em que lideraram o maio de 68. Sabemos, hoje, que este discurso está confortavelmente enquadrado no âmbito da excepção socialmente permitida o campo das artes e que esta traiçăo levaria Debord a citar Arthur cravan: "pronto no veremos en la calle más que a artistas, y no será nada fácil encontrar a un hombre".

> Provavelmente Constant nunca deixou de ser artista (do mesmo modo que nós nunca deixámos de ser arquitectos) i Tudindo-se a si próprio com o pretexto de uma revoluçăo cultural até chegar a um narcisismo ou desilusão (na perspectiva de Mark Wigley (20)), na elaboração de um imaginário ou utopia. Mas, também Debord, insistiria em reivindicar algo demasiado abstracto (21) - a libertação do homem de uma sociedade alienada e controlada por senhores - partindo do pressuposto que o espectáculo nos é impingido de um modo obscuro ou subti1. o que parecia secretamente manipulado por poucos, aparece-nos, agora, abertamente exposto sob uma cumplicidade social generalizada, que conhece as regras de um poder demasiado disperso para que se denomine. Também paradoxalmente, a declaraçăo de guerra, levada a cabo pelos situacionistas, às militâncias cegas e partidárias (supostamente responsáveis pela alienação do indivíduo), coincidiram com a construção de um vazio ideológico que não teve como consequência uma fortificaçăo do indivíduo (socialmente responsáve1, como imaginava Debord) mas sim uma fortificação do individualismo (socialmente indiferente). Assistimos, ainda, a uma dissipação da sociedade de classes em sociedade de micro-classes; sem contudo se dissiparem profundas desigualdades. E, paradoxalmente, assiste-se, a uma maior valorizaçăo do tempo livre e do ócio; sem contudo representar maior realização e criação pessoal. 
1 "Formulary for a new Urbanism" In Theory of the Dérive and other situationist writings on the city, MACBA/ACtar, Barcelona, 1996 (Pág. 14),

2 "o estado de amplificaçẫo da poesia finalizava com victor Hugo, na continuaçầo, Baudelaire destruiu a narrativa em favor da forma poética; verlaine destruiu a forma poética em favor do verso puro; Rimbaud destruiu o verso a favor da palavra; Mallarmé devolveu a palavra ao som; Tristan Tzara destruiu a palavra a favor do vazio; Isou resgataria a letra da palavra a letra cono puro signo, aparentemente sem significado mas interminavelmente fecundo" ( Isidore Isou citado em MARCus, Greil. Rastros de (armín, Pág. 266.)

30 falso dominicano seria um joven de 22 anos, Michel Mourre, acompanhado de serge Berna e Ghislain de Marbaix, que entre outras "heresias" acusava a Igreja católica, perante dez mil pessoas, de infectar o mundo com a sua moralidade fúnebre, de prometer um céu vazio (antecipando-se à própría igreja en 49 anos), por último proclanava a morte de Deus e Cristo para que o homem pudesse finalmente viver. Resgatados pela polícia de um populaçăo enraivecida os letristas conseguia a publicidade desejada.

4 "o filme foi estreado no Museu do Homem a 30 de Junho de 1952, aos vinte minutos foi interrompida a projecção, vários elementos do grupo letrista saíram da sala sob forma de protesto por Isou ter aprovado tamanha atrocidade". MARCus, Greil. Rastros de Carmín (pág. 354), Outro escânda o provocado pela Internacional Letrista foram os panfletos distribuídos por Debord, Serge Berna, Jean-L. Brau e Gil 3. wolman, na chegada de charlie chaplin a Paris. O Actor tinha sido proibido de regressar aos EUA numa altura em que era acusado de subversåo (Nixon em vésperas de eleiçōes acusava os democratas de serem demasiado brandos com os conunistas), a Europa recebia chaplin de braços abertos mas os Letristas acusaram-no de ser um chantagista emocional, maestro-cantor da desgraça, insecto fascista e de estar relacionado com a alta sociedade; "Morre depressa, que te fazemos um funeral de primeira classe, rezamos para que o teu último filme seja mesmo o último", dizia o manifesto distribứdo após romper a barreira policial que cercava o Hotel Ritz. Para os Letristas o cinema de chaplin, embora retrato do homem oprimido, năo deíxava de fazer parte de um espectáculo inofensivo, incapaz de gerar uma revolução social. Este posicionamento radical iria comprometer a posiçăo de Isidore Isou que nẳo deixava de reconhecer nos filmes de chaplin um trabatho criativo invioláve1. Debord abria deste modo o seu próprío caminho: "onde há fogo, nós levamos gasolina"
5 "El arte debía ser el lenguaje de la comunicación, pero la pérdida progresiva de todas las condiciones de la comunicación ha llevado al lenguaje el de la literatura y las artes figurativas a constatar precisamente la impossibilidad de la comunicación. Durante el proceso de destrucción de todos los valores formales que se prolongó desde Baudelaire hasta Joyce y Malevitch, el arte fue acentuando cada vez más su negativa a ser el Tenguaje ficticio de una comunidad inexistente." "Debord pasa revista a los progresos de la consciencia que han realizado con el futurisno, el dadafsmo - cuya disolución fue inevitable debido a su definición enterament negativa, pero cuya aportación reaparece en todas las vanguardias posteriores y el surrea1ismo. Elogiando la riqueza de 1 programa surealista primitivo, Debord identifica la sobrevaloración del inconsciente como fuente de la degeneración de 1 movimento. Cuando la burguesía recupera el elogio surrealista de lo irracional para embellecer o justificar la completa irracionalidad de su mundo, estamos ante un ejemplo particularmente 11 amativo de la función enteramente distinta que Tas viejas vanguardias pasan a cumplir después de 1945 . Lo que era una protesta contra el vacio de la sociedad burguesa se encuentra ahora fragmentado y disuel to en el comercio estético corriente, como una afirmación positiva de ese vacío." "La decomposición cambia entonces de significado y entra a formar parte de los intentos burgueses de conservar el arte como um objeto muerto de contemplación. Desligada de la necesidad de reencontrar en la práctica un lenguaje nuevo, Ta autodestruccíón de l lenguaje queda srecuperadaw por 1a adefensa del poder de classes" (JAPPE, Anselm. Guy Debord, pág, 80 e 87)

6 "Psychogeography could set for itself the study of the precise laws and specific effects of the geographical environment, consciously organized or not, on the emotions and behavior of individuals." (Guy Debord, "Intruduction to a critique of urban Geography" (1955) in Theory of the dérive and other situationist writings on the city)

7 Guy Debord, "Theory of the dérive" (1956) in Theory of the dérive and other situationist writings on the city.

8 Miquel Molins, editorial de Situacionistas, Arte, politica, urbanismo

9 r.s. $n .{ }^{\circ} 3$ de 1959, inti tulado o urbanismo unitário no fim dos anos 50 reeditado em Internacional Situacionista - Antologia, organizada por Júlio Henriques (pág 54).

10 "o socialismo, que tende para a mais completa libertaçâo das energias e capacidades de cada individuo, será obrigado a ver na automatização uma 
tendência antiprogressista en si, transformada em tendência progressista unicamente pela relaçăo que estabelece com novos estimulos capazes de exteriorizar as energias latentes do homem. Se é verdade como pretenden os cientistas e os técnicos, que a automatizaçâo constitui um novo meio de libertaçăo do homem, ela tem de implicar uma superaçẫo das anteriores actividades humanas. coisa que obriga a imaginaçăo activa do homem a ultrapassar a realizaçăo da própría autonatizaçăo. ora onde vemos nós essas tais perspectivas capazes de tornar o homem senhor e năo escravo da automatizaçăo?" (Asger Jorn, "os situacionistas e a Automatizaçăo" x.S. $n^{\circ}$ 1 Junho 1958)

11 os situacionistas chaman détournement a uma prática de desvio, apropriaçấo, reciclagem, ou reorganizaçăo de elementos preexistentes, que essencialmente sofrem uma descontextualizaçăo, traindo o seu significado original. Desde logo os situacionistas se aperceberam dessa arma capaz de subverter o território inimigo por dentro: "qualquer signo, qualquer rua, anúncio, quadro, texto, qualquer representaçăo da ideia de felicidade que tem a sociedade é susceptível de converter-se em outra coisa, inclusivo no seu oposto" (Debord e wolman, 1956 citados por Greil Marcus em Rastros de Carmín, Pág. 193). Do mesmo modo que constant trabalha sobre uma car-tografia existente, apropriando-se da realidade para the atribuir outro sentido, poderíanos considerar ainda os trabalhos de Asger Jorn; pintura sobre pinturas existentes, ou os filmes de Debord en que são usadas imagens retiradas da televisăo $\mathrm{e}$ colocadas num contexto critico e oposto ao seu sentido original. Esta prática era ainda notória nas ilustraçōes das publicaçōes da I.S. na descontextualizaçăo de anúncios publicitários ou na alteraçăo das legendas e balōes de tiras de banda desenhada ou ainda na citaçăo literária subvertida. Trata-se, portanto de um desvio da produçăo artística convencional. Este conceito andará muito próximo do conceito de ready-made rectificado ou assistido, de Marcel Duchamp, cono Apolinère Enaneled (1916/1917) aproveitamento de un anúncio à pintura de esmalte sapolin. "Détournement short for: détournement of preexisting aesthetic elements. The integration of present or past artistic production into a superior construction of a milieu. In this sense there can be no situationist painting or music, but only a situa-tionist use of these means. In a more primitive sense, détournement within the old cultural spheres is a method of propaganda, a method which testifies to the wearing out and loss of importance of those spheres" in I.S $n^{\circ} 1,1958 . " 0$ desvio é o contrário da citaçăo, da autoridade teórica sempre falsificada, pelo pró.prio facto de ela se ter tornado citaçăo; fragmento arrancado ao seu contexto, ao seu movimento, e, finalmente, à sua época, como referência global e à opçăo precisa que ela constituia no interior desta referência, exactamente reconhecida ou errónea. o desvio è a linguagem fluida da anti-ideologia. Ele aparece na comunicaçăo que sabe não poder deter nenhuma garantia em sí própria e definitivamente. Ele é, no maís alto ponto, a linguagem que nenhuma referência antiga e supracrítica pôde confirmar. É, pelo contrário, a sua própria coerência, en si próprio e para com os factos praticáveis, que pode confirmar o antigo núcleo de verdade que ele volta a trazer conșigo. o desvio não fundou a sua causa sobre nada de exterior à sua própria verdade como crítica presente" Guy Debord in A Sociedade do Espectáculo (1967), paragrafo 208. Ainda sobre o conceito détournement, afirma Anselm Jappe, que toda a concepção sociał de Debord se baseia em détournenent: tanto na cultura como na técnica e que ao contrário da colagem dadaista que se Timita a uma desvalorizaçăo dos elementos, Debord propōem, com optimismo, uma dialéctica de desvalorização e valorizaçāo negando «o valor da organização anterior à expressâom superando a pura negatividade que tinha caracterizado o dadaísmo.

12 o título deste texto racional aperfeiçoamento exibe um claro afastamento as propostas surrealistas presentes nas possibilidades do Aperfeicoamento Irracional de uma cidade (mani-festo de 1932), Mais do que irracionalidade os situacionistas buscavam consciência (ver, por exemplo o sentido de dérive), também porque sabiam que a Toucura surrealista já teria sido totalmente absorvida pelo imaginário burguês.

13 "Ne travaillez jamais" frase de Debord, inspirada em Rimbaud, ou nos surrealistas que declaravam "guerra ao trabalho" na revista La Révolution surréalist $n^{\circ} 4$. (Anselm Jappe Guy Debord, Pag. 112). A frase seria diversas vezes usada na revoluçăo de Maio de 68 que juntava à insubordinaçăo a expectativa da automatizaçáo tecnológica vir libertar o homem da escravidão do trabalho. Mas é desde logo na Internaciona1 Letrista que aparece associada a um manifesto "Uma Ideia Nova Na Europa" ( Potlatch \#7, Agosto de 1954): "o ócio é a verdadeira questão revolucionária (...) tendo passado năo sei quantos anos sen fazermos nada, no sentido mais corrente do termo, podemos falar da nossa atitude social como sendo de vanguarda, porque numa sociedade todavia provisoriamente baseada na produção, temos procurado dedicar-nos exclusivamente ao ócio." ver também Rastros de Carmin de Greil Marcus (pág. 368). 14 usual referência de constant aos projectos de Le corbusier. 
15 "Critique of Urbanism" I.S. $n^{\circ} 6$ (1961) in Theory of the dérive and other situationist writings on the city.

16 "Guy Debord followed André Breton's exemple. People were expelled. I was never part of the group. I could have been, but $i$ was careful, since $i$ knew Guy Debord's character and his manner, and the way he had of imitating André Breton, by expelling everyone in order to get at a pure and hard little core. In the end the menbers of situationist international were Guy De-bord, RaouT Vaneigem, and Michèle Bernstein. " ( Henri Lefebvre, october n. ${ }^{\circ}$ 79.) 17 constant adoptava a atitude de um arquitecto, sem contudo deixar de reforçar a identidade de artista. o empenhamento dispensado na execuçăo de litografias e boletins informativos, contribuira para a imagem de persona hy-per-architectural (WIGLEY, Mark. Constan's New Babylon, pág. 62) 18 VIDAL, Carlos. "Guy-Ernest Debord, a Deriva cono Liberdade, a Liberdade como Deriva (a cançăo continua)" in Colóquio-Artes, Abri1/Junho de 1995.

19 Parágrafo 172 de A Sociedade do Espectáculo. 20 ver Também entrevista a Mark wigley publicada na In $\mathrm{si}(\mathrm{s})$ tu $\# 0.2$ veiculos.

21 Próximo do sentido que descreve Giorgio Agamben as reivindicaçöes de Tian an Men: "Democracia y $1 i$ berdad son nociones denasiado genéricas como para construir un objecto real de conflicto" in "violencia y Esperanza en el vitimo Espectáculo" in situacionistas, Arte, Po-lítica, urbanismo.
Andreottí, Libero. e COSTA, Xavier. Situacionistas, Arte, Poliftica, urbanismo. Ed. Actar, Barcelona, 1996.

Banham, Reyner. Megaestruturas: Futuro urbano del Pasado Reciente, Ed. Gustavo Gili, barcelona, 1978. Debord, Guy. A sociedade do Espectáculo, Ed, Mobi7 is in Mobile, Lisboa, 1991 ( $2^{a}$ ed.).

Debord, Guy. comentarios sobre la sociedad del Espectáculo, Ed. Anagrama, Barcelona, 1999.

Debord, Guy. Panegírico, Ed. Antigona, Lisboa, 1995.

Debord, Guy. Relatório sobre a construçăo de situaçōes, Ed. Ferândola, Paris, 1999.

Debord, Guy. Girum Imus Nocte et Consumimur igni Damos vueitas en la Noche y Somos devorados por e? Fuego, Ed. Al Margen, Barcelona, 1999.

Henriques, súlio. Internacional sttuacionista Antologia, Ed. Antígona, Lisboa, 1997.

Jappe, Anse1m. Guy Debord, Ed. Anagrama, Barcelona, 1998.

Jarauta, Francisco. Conferência "Emergencia e Intervencionismo", gravaçăo audio. Maçba, Barcelona, 1996.

Jarauta, Francisco. Globalización y Fragmentación del Mundo Contemporáneo, Ed. Gipuzkoako Foru Aldundia, Donostia, 1996.

Lefebvre, Henri. "Entrevista de Kristian Ross" in october \# 79. Ed, MIT Press, 1997.

Lefebvre, Henri. Writings on Cities, Ed. Blackwe11, oxford, 1997 ( $2^{\mathrm{a} e d}$ )

Marcus, Grei1, Rastros de Carmin, Ed. Anagrama, Barcelona, 1993.

vidal, Carlos. "Guy-Ernest Debord- a Deriva como Liberdade e a Liberdade como Deriva", ' in ColóquioArtes, Abri1/Junho, Ed. FCG, Lisboa, 1995.

Wigley, Mark. Constant's New Babylon, Ed, 010, Rotteram, 1998.

wigley, Mark. "Nova Babilônia entrevista", in In si (s) to $\$ 0.2$, Julho/Outubro, Ed. ACI, Porto, 2001 (varios) Theory of the Dérive and other situationist writings on the City, Ed. MACBA/ACtar, BarceIona, 1996. 